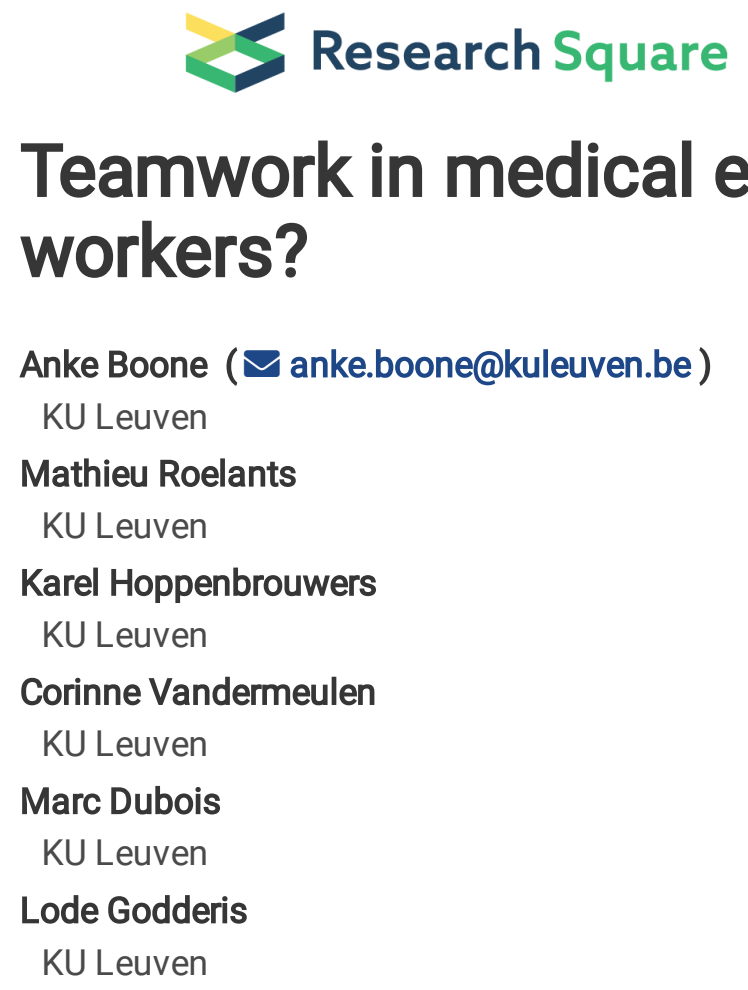

Anke Boone ( $\square$ anke.boone@kuleuven.be )

KU Leuven

\section{Mathieu Roelants}

KU Leuven

\section{Karel Hoppenbrouwers}

KU Leuven

\section{Corinne Vandermeulen}

KU Leuven

Marc Dubois

KU Leuven

Lode Godderis

KU Leuven

\title{
Teamwork in medical education: are medical students team workers?
}

\section{Research Article}

Keywords: Teamwork, Medical Education, Curriculum, Medical Students, Healthcare

Posted Date: November 9th, 2021

DOI: https://doi.org/10.21203/rs.3.rs-1048090/v1

License: @ (i) This work is licensed under a Creative Commons Attribution 4.0 International License. Read Full License

Version of Record: A version of this preprint was published at Safety and Health at Work on January 1st, 2022. See the published version at https://doi.org/10.1016/j.shaw.2021.12.1075. 


\section{Abstract}

Introduction. Despite the increasing importance of teamwork in healthcare, medical education still puts great emphasis on individual achievements. The purpose of this study is to examine medical students' team role preferences, including the association with gender and specialty; and to provide implications for policy makers and medical educators.

Methods. We used an exploratory methodology, following a repeated cross-sectional design. Data was collected from first year master students in medicine $(n=2293)$ during five consecutive years $(2016-2020)$. The Belbin Team Role Self Perception Inventory (BTRSPI) was used to measure medical students' self-perceptions of their team role.

Results. The Team Worker was the most preferred team role among medical students (35.8\%), regardless of study year, gender or specialty. Female and male students had similar team role patterns, although female students scored higher on Team Worker $(40.4 \%$ vs. $29.1 \%, p<0.001)$ and Completer-Finisher $(14.0 \%$ vs. $8.0 \%, p<0.001)$.

Conclusions. Our findings are encouraging due to the increased importance of interdisciplinary collaborations in healthcare. Nevertheless, policy makers and medical educators should prioritize teamwork skills at all stages (i.e. admission to residency) and levels (i.e. in the explicit and implicit curriculum) to ensure their continued development throughout the educational process.

\section{Highlights}

- Team worker is the most frequently preferred team role among medical students, regardless of study year, gender or specialty.

- Female students scored higher on the Team Worker role compared to male students.

- Team Workers were more present in future general practitioners and lower in technique-oriented specialties, with students who chose a person-centered specialty in the middle.

- Medical education should stimulate teamwork skills throughout the entire curriculum.

\section{Introduction}

The importance of teamwork in healthcare is becoming increasingly apparent (Hall and Weaver 2001). The growing complexity of patient care and the surge in comorbidities have resulted in an increase in medical specializations (i.e. among medical doctors, nurses, psychologists, etc.) (Hall and Weaver 2001; Hall 2005). To overcome specialty fragmentation, multidisciplinary healthcare teams have become the solution, characterized by strong collaborations between different medical specialties (e.g. general practitioners, surgeons) and health professions (e.g. medical doctors, nurses) (Hall and Weaver 2001). Effective teamwork has been found to be beneficial for a variety of additional reasons, such as increased work-engagement (Montgomery et al. 2015), lower burn-out risk, higher performance and fewer medical errors (Rosen et al. 2018). However, it is important to note that effective teamwork becomes more challenging with the rise in specializations, as different medical specializations have distinct interests, technical jargon and educational backgrounds (Hall 2005).

Evidence on medical doctors' teamwork skills shows they are usually not considered team workers, but rather solo performers and independent decision-makers (Gabbard 1985; Reuben et al. 2004; Whitehead 2007). They have a tradition of working independently and are trained to take full responsibility as medical experts (Gabbard 1985; Reuben et al. 2004; Whitehead 2007; Saba et al. 2012). Nevertheless, former studies indicate differences in gender (Anderson and Sleap 2004; Walkiewicz et al. 2018) and medical specialties (Reuben et al. 2004). For instance, women are usually better team workers compared to men, while men generally score higher on leadership (Anderson and Sleap 2004; Walkiewicz et al. 2018).

Additionally, certain medical specialties have a longer tradition of teamwork (Reuben et al. 2004) or require higher levels of 
empathy (Chen et al. 2007), which is an important characteristic of teamwork (Hojat et al. 2015). For example, medical students who prefer general practice or person-centered specialties (e.g. psychiatry) usually have higher empathy scores than those who prefer technique-oriented specialties (e.g. clinical biologist) (Chen et al. 2007).

To ensure high-quality healthcare, teamwork has been increasingly identified and incorporated into curricula for medical education (Chakraborti et al. 2008). The Canadian Medical Educational Directives for Specialists (CanMEDS) developed an outcomes-based framework for medical education that identifies seven core competencies for medical doctors, including the Collaborator (Frank et al. 2015). The Collaborator is described as someone who works 'effectively with other health care professionals to provide safe, high-quality, patient-centred care' (Frank et al. 2015, 18). Belgium, Denmark, Australia and New Zealand are among the countries that have adopted this framework as a guideline for medical education curricula (Ringsted et al. 2006; KU Leuven 2021).

Despite this progress, medical education is still marked by strong competitiveness (e.g. numerus clausus) and a focus on individual achievements and outcompeting peers (Coulehan and Williams 2001; Saba et al. 2012; Yates 2012; Chandrashekar and Mohan 2019; Colebatch et al. 2019). Evidence has indicated that medical students perceive healthcare as an individual responsibility rather than a collective one (Horsburgh et al. 2006). In addition, Walkiewicz et al. (2018) showed that medical students scored higher on action-oriented team roles (i.e. concerned with immediate tasks) and thinking-oriented roles (i.e. creative or analytical thinkers) than on the team worker role (Walkiewicz et al. 2018), which CanMEDS refers to as the Collaborator (Frank and Danoff 2007). Furthermore, multiple studies have found that empathy scores decreased throughout medical education (Chen et al. 2007; Newton et al. 2008; Hojat et al. 2009; Lim et al. 2013). These findings contradict with the increasing importance of interprofessional collaboration and multidisciplinary teamwork in modern healthcare (Saba et al. 2012; Chandrashekar and Mohan 2019).

There is also still much uncertainty on medical students' perceptions with regard to their own professional team roles. We have been able to identify only one study by Walkiewicz et al. (2018), but the generalizability of their findings was problematic due to the relatively small sample size. Nonetheless, examining perceptions has great value as studies have shown that people who have positive perceptions about teamwork tend to be more committed to it (Mendo-Lázaro et al. 2017; Puente-Palacios and De Souza 2018). Furthermore, perceptions and beliefs mainly result from past experiences, which means that providing positive experiences (i.e. on teamwork) may improve people's commitment towards teamwork in the future (Puente-Palacios and De Souza 2018).

The aim of this study is to examine self-perceptions of medical students on their professional team role, with a focus on teamwork. In addition, we have assessed differences according to gender and future specialty (i.e. general practice, personcentered specialty or technique-oriented specialty). Based on the literature, we expected overall higher scores for actionoriented and thinking-oriented roles versus team worker roles (Walkiewicz et al. 2018); and higher scores for team worker roles in female students (Anderson and Sleap 2004; Walkiewicz et al. 2018) and in those who will later opt for a training as general practitioner or a person-oriented specialty (Chen et al. 2007).

\section{Materials And Methods}

\section{Participants}

First year master students in medicine of the University of Leuven, Belgium (KU Leuven), were asked to complete an online questionnaire prior to starting a group assignment during five consecutive years from 2016 to 2020 . The number of students enrolled per year was 487 (2016), 502 (2017), 464 (2018), 469 (2019) and 514 (2020). The total number was 2.436 students, of which $60 \%$ were female. In December of each year, designated faculty members sent the questionnaire to the students via email with a link to the survey, and a reminder was sent in January. The submission of the questionnaire was part of a curriculum activity that did not require approval from the Ethics Committee. For the analysis of associations 
of team roles with gender and specialty, ethical approval was obtained from the Social and Societal Ethics Committee of the KU Leuven (G-2020-1632). To ensure anonymity and privacy, data were pseudonymized (i.e. personal identification data were replace by a code prior to the analysis).

\section{Instrument}

The Dutch version of the Belbin Team Role Self Perception Inventory (BTRSPI) was used to measure self-perceptions on team roles. This questionnaire is based on Belbin's Team Role model, which assesses behaviour instead of job ranking, position or personality (Belbin 2012). Table 1 describes the eight different team roles according to Belbin: Completer-

Finisher, Shaper, Implementer, Monitor-Evaluator, Plant, Resource-Investigator, Team Worker and Coordinator. Later, a ninth team role - the Specialist - was added based on specialist expertise. However, the Dutch BTRSPI did not include this role, and because our research primarily focused on teamwork, we included only eight Belbin team roles (Belbin 2012). 
Table 1

Belbin Team Roles, Focus, Strengths and Weaknesses

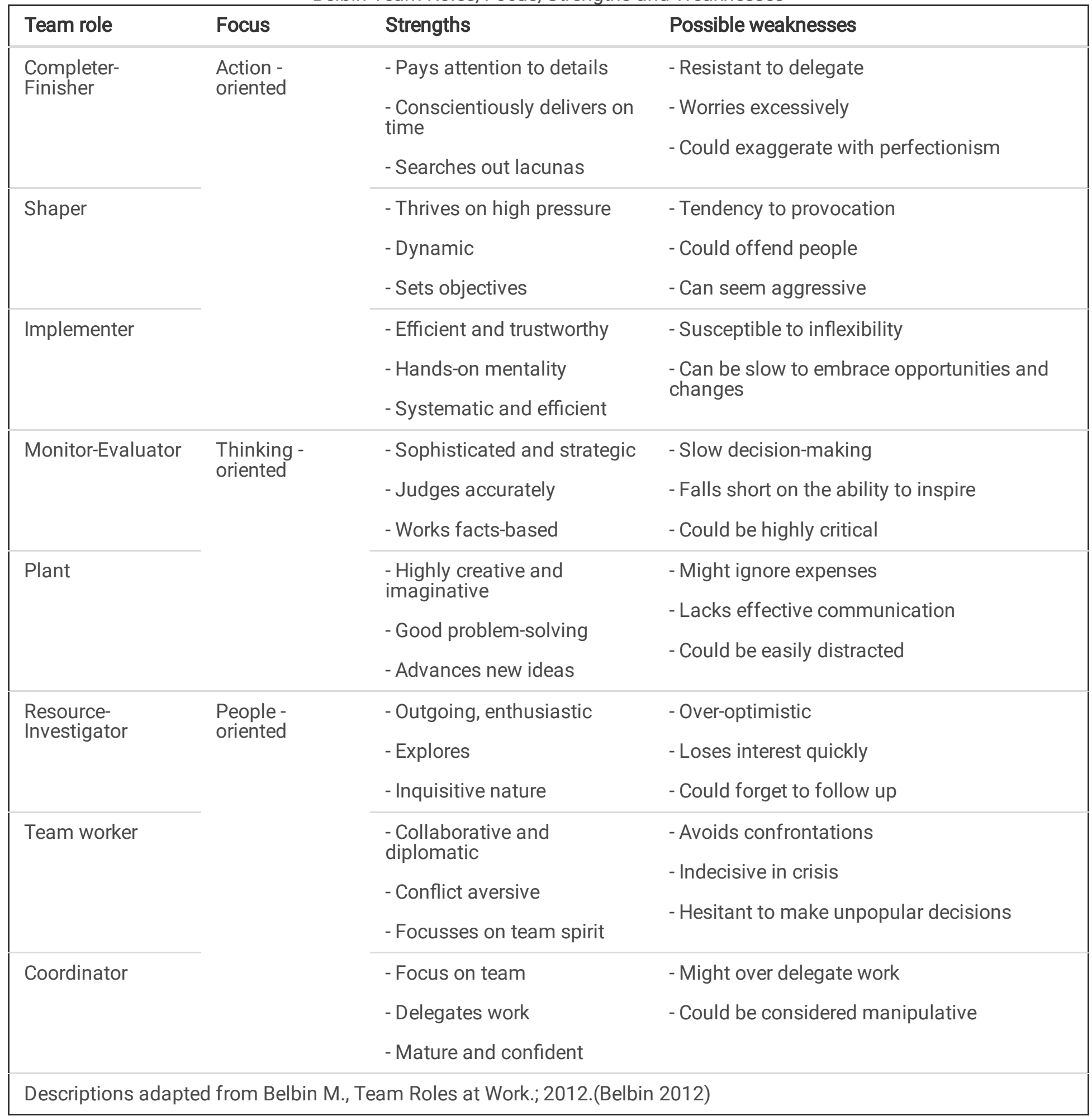

The questionnaire was distributed with the online survey program LimeSurvey version 2.06+ (LimeSurvey GmbH, Hamburg, Germany) for the first four years (2016-2019), and with Qualtrics (Qualtrics, Provo, UT, USA) in 2020. The BTRSPI is divided into seven categories. For each category, students have to assign a total of 10 points among eight items, based on how closely each item represents the respondent's self-perceived behaviour. Each item relates to one of Belbin's team roles in particular. An example is 'I believe I can make positive contributions to a team because... [item 1/8: I am quick to see and take advantage of new opportunities]. This item corresponds with the Monitor-Evaluator. The more points a student assigns to a particular item, the better this behaviour matches the self-perceived team role. The scores which correspond to a given 
team role in each of the seven categories are combined, and the highest score represents the preferred team role, while the lowest score reflects the least corresponding team role (Aritzeta et al. 2007; Belbin 2012).

\section{Data analysis}

Data were analyzed in R version 4.0 (R Core Team 2020). The primary outcome variable of our analysis was the preferred team role, defined as the team role with the maximum score. When multiple (usually two) team roles received the same maximum score (i.e. ties), each one of these roles was considered as 'preferred' such that the total prevalence is somewhat larger than $100 \%$ (i.e. $113.6 \%$ ). Preferred team roles were compared separately by gender, academic year and specialty with chi-squared tests. In addition, total scores for each of the roles were compared using Spearman correlation analysis. Statistical tests with a p-value lower than 0.05 were considered as statistically significant.

Specialty analysis was limited to the cohorts of 2016 and 2017 since later cohorts had not yet started further training and education. For this analysis, medical specialties were grouped as General Practitioners (GP), Person-oriented Specialties (PS: internal medicine, gynecology, physical medicine and rehabilitation, pediatrics and psychiatry), and Technique-oriented Specialties (TS: surgery, neuro-surgery, orthopedic surgery, esthetical surgery, otolaryngology, ophthalmology, anesthesiology, dermatology, emergency medicine, pathology, radiography, insurance medicine, clinical biology, clinical genetics, nuclear medicine, urology and stomatology) (Borges and Richard 2018).

\section{Results}

We received 2293 answers to our online survey (global response rate 94\%). The number of participants/total number of students enrolled for the course in the five cohorts was 467/487 (96\%) in 2016, 475/502 (95\%) in 2017, $429 / 464$ (92\%) in $2018,457 / 469$ (97\%) in 2019 and 465/514 (90\%) in 2020. The mean age of the students was 21.7 years (SD 2.0) and $60 \%$ $(n=1375)$ were female.

Team roles (Figure 1). The Team Worker was by far the most popular team role, receiving the highest score from 822 respondents (35.8\%). The Implementer ranked second with 555 respondents (24.2\%) and the Shaper third with 447 respondents (19.5\%). The two least prevalent team roles were the Resource-Investigator $(n=54,2.4 \%)$ and the Plant $(n=67$, $2.9 \%$ ). Differences between the five cohorts were small and not statistically significant $(p>0.05)$ (see Table 3 ). A total of 277 respondents $(12.1 \%)$ had two or more preferred team roles. 
Table 2

Team Roles according to the five consecutive years $(2016,2017,2018,2019,2020)$

\begin{tabular}{|c|c|c|c|c|c|c|c|c|c|c|c|c|c|}
\hline & \multicolumn{2}{|c|}{2016} & \multicolumn{2}{|c|}{2017} & \multicolumn{2}{|c|}{2018} & \multicolumn{2}{|c|}{2019} & \multicolumn{2}{|c|}{2020} & \multicolumn{2}{|l|}{ Total } & \multirow{2}{*}{$\begin{array}{l}P- \\
\text { value }\end{array}$} \\
\hline & $\mathbf{N}$ & $\%$ & $\mathbf{N}$ & $\%$ & $\mathbf{N}$ & $\%$ & $\mathbf{N}$ & $\%$ & $\mathbf{N}$ & $\%$ & $\mathbf{N}$ & $\%$ & \\
\hline $\begin{array}{l}\text { Completer- } \\
\text { Finisher }\end{array}$ & 45 & 9.6 & 55 & 11.6 & 44 & 10.3 & 65 & 14.2 & 56 & 12.0 & 265 & 11.6 & 0.224 \\
\hline Shaper & 87 & 18.6 & 82 & 17.3 & 74 & 17.2 & 110 & 24.1 & 94 & 20.2 & 447 & 19.5 & 0.053 \\
\hline Implementer & 104 & 22.3 & 126 & 26.5 & 111 & 25.9 & 110 & 24.1 & 104 & 22.4 & 555 & 24.2 & 0.425 \\
\hline $\begin{array}{l}\text { Resource- } \\
\text { Investigator }\end{array}$ & 11 & 2.4 & 17 & 3.6 & 12 & 2.8 & 7 & 1.5 & 7 & 1.5 & 54 & 2.4 & 0.180 \\
\hline $\begin{array}{l}\text { Team } \\
\text { worker }\end{array}$ & 184 & 39.4 & 178 & 37.5 & 156 & 36.4 & 145 & 31.7 & 159 & 34.2 & 822 & 35.8 & 0.131 \\
\hline Coordinator & 42 & 9.0 & 38 & 8.0 & 36 & 8.4 & 37 & 8.1 & 32 & 6.9 & 185 & 8.1 & 0.829 \\
\hline $\begin{array}{l}\text { Monitor- } \\
\text { Evaluator }\end{array}$ & 41 & 8.8 & 47 & 9.9 & 36 & 8.4 & 39 & 8.5 & 45 & 9.7 & 208 & 9.1 & 0.903 \\
\hline Plant & 13 & 2.8 & 12 & 2.5 & 14 & 3.3 & 13 & 2.8 & 15 & 3.2 & 67 & 2.9 & 0.960 \\
\hline Team roles & 527 & 112.9 & 555 & 116.9 & 483 & 112.7 & 526 & 115 & 512 & 110.1 & 2603 & 113.6 & \\
\hline \multicolumn{14}{|l|}{$* P<0.05$} \\
\hline ** $P<0.001$ & & & & & & & & & & & & & \\
\hline
\end{tabular}

Gender (Table 3). Female and male students showed overall similar team role patterns, while more female than male students preferred the Team Worker $(40.4 \%$ vs. $29.1 \%, p<0.001)$ and Completer-Finisher role $(14.0 \%$ vs. $8.0 \%, p<0.001)$. Male students, on the other hand, more often preferred the Monitor-Evaluator role than female students $(14.1 \%$ vs. $5.7 \%, p<$ 0.001).

Specialty (Table 3). The Team Worker was the most preferred team role among students who later opted for a training as a General Practitioner (GP) (47.1\%), a Person-centered Specialty (PS) (41.8\%) and a Technique-centered Specialty (TS) $(29.1 \%)$. However, the frequency was largely different between disciplines, with the Team Worker role more often chosen by GPs than by PS and TS; and more often by PS than by TS $(p<0.001)$. Among students who opted for TS, the Team Worker role was only marginally more preferred than the Shaper or Implementer role, while Team Worker had a greater advantage on the next team role among GP and PS. Further, Shaper and Completer-Finisher were significantly more preferred team roles among TS, than among GP or PS $(p<0.05)$. 
Table 3

Preferred Team Roles according to Gender and Specialty Group

\begin{tabular}{|c|c|c|c|c|c|c|c|c|c|c|c|c|}
\hline \multirow[t]{2}{*}{ Team roles } & \multicolumn{2}{|c|}{ Female } & \multicolumn{2}{|c|}{ Male } & \multirow[t]{2}{*}{ P-value } & \multirow{2}{*}{$\begin{array}{l}\text { GP } \\
\mathbf{N}\end{array}$} & \multicolumn{2}{|c|}{ PS } & \multicolumn{3}{|c|}{ TS } & \multirow[t]{2}{*}{ P-value } \\
\hline & $\mathbf{N}$ & $\%$ & $\mathbf{N}$ & $\%$ & & & $\%$ & $\mathbf{N}$ & $\%$ & $\mathbf{N}$ & $\%$ & \\
\hline Completer-Finisher & 192 & 14.0 & 73 & 8.0 & $0.000 * \star$ & 26 & 9.0 & 20 & 10.2 & 34 & 16.5 & $0.028 *$ \\
\hline Shaper & 253 & 18.4 & 194 & 21.1 & 0.118 & 42 & 14.5 & 35 & 17.9 & 54 & 26.2 & $0.004^{*}$ \\
\hline Implementer & 337 & 24.5 & 218 & 23.7 & 0.713 & 61 & 21.1 & 43 & 21.9 & 56 & 27.2 & 0.256 \\
\hline Resource-Investigator & 24 & 1.7 & 30 & 3.3 & $0.027 *$ & 10 & 3.5 & 7 & 3.6 & 2 & 1.0 & 0.176 \\
\hline Team Worker & 555 & 40.4 & 267 & 29.1 & $0.000 * \star$ & 136 & 47.1 & 82 & 41.8 & 60 & 29.1 & $3 e-04^{\star *}$ \\
\hline Coordinator & 100 & 7.3 & 85 & 9.3 & 0.102 & 28 & 9.7 & 18 & 9.2 & 12 & 5.8 & 0.279 \\
\hline $\begin{array}{l}\text { Monitor- } \\
\text { Evaluator }\end{array}$ & 79 & 5.7 & 129 & 14.1 & $0.000 * \star$ & 16 & 5.5 & 19 & 9.7 & 22 & 10.7 & 0.084 \\
\hline Plant & 28 & 2.0 & 39 & 4.2 & $0.003^{\star}$ & 8 & 2.8 & 5 & 2.6 & 2 & 1.0 & 0.365 \\
\hline $\begin{array}{l}\text { GP: general practitioner } \\
\text { is limited to students } \mathrm{fr} \\
\text { * } \mathrm{P}<0.05 \\
\text { ** } \mathrm{P}<0.001\end{array}$ & 20 & $\begin{array}{l}\text { in o } \\
\text { nd }\end{array}$ & ted & إن & : Tech & & ed $s$ & & he & & $\mathrm{cr}$ & ty group \\
\hline
\end{tabular}

Correlations (Table 4). A Spearman correlation analysis of scores given to the various team roles was conducted. This analysis indicated a moderate significant (negative) correlation between Team Worker and Shaper $\left(r_{s}=-0.582, p<0.001\right)$, which means that the higher a respondent's Team Worker score is, the lower their Shaper score. Other significant (negative) correlations appeared, although they were rather weak $\left(r_{s}<-0.400\right)$ (Akoglu 2018) (e.g. Resource-Investigator vs. CompleterFinisher, Resource-Investigator vs. Implementer, Coordinator vs. Completer-Finisher, Plant vs. Shaper). 
Table 4

Spearman Correlations between Team Roles (above diagonal) and corresponding p-values (below diagonal)

\begin{tabular}{|c|c|c|c|c|c|c|c|c|}
\hline & $\begin{array}{l}\text { Completer- } \\
\text { Finisher }\end{array}$ & Shaper & $\begin{array}{l}\text { Imple- } \\
\text { menter }\end{array}$ & $\begin{array}{l}\text { Resource- } \\
\text { Investigator }\end{array}$ & $\begin{array}{l}\text { Team } \\
\text { Worker }\end{array}$ & $\begin{array}{l}\text { Coordi- } \\
\text { nator }\end{array}$ & $\begin{array}{l}\text { Monitor - } \\
\text { Evaluator }\end{array}$ & Plant \\
\hline $\begin{array}{l}\text { Completer- } \\
\text { Finisher }\end{array}$ & & -0.043 & 0.066 & -0.372 & -0.143 & -0.335 & -0.209 & -0.117 \\
\hline Shaper & $0.041^{\star}$ & & -0.218 & 0.001 & -0.582 & 0.155 & -0.063 & -0.330 \\
\hline $\begin{array}{l}\text { Implemen- } \\
\text { ter }\end{array}$ & $0.002^{*}$ & 0.000 ** & & -0.320 & 0.023 & -0.235 & -0.025 & -0.175 \\
\hline $\begin{array}{l}\text { Resource- } \\
\text { Investigator }\end{array}$ & $0.000 * *$ & 0.966 & $0.000 \star \star$ & & -0.079 & 0.119 & -0.082 & 0.179 \\
\hline $\begin{array}{l}\text { Team } \\
\text { Worker }\end{array}$ & $0.000 * *$ & $0.000 * *$ & 0.271 & $0.000 * \star$ & & -0.091 & -0.230 & 0.026 \\
\hline Coordinator & 0.000 ** & $0.000 * \star$ & 0.000 ** & $0.000 * *$ & $0.000 * \star$ & & -0.100 & -0.219 \\
\hline $\begin{array}{l}\text { Monitor- } \\
\text { Evaluator }\end{array}$ & $0.000 * \star$ & $0.003 *$ & 0.221 & $0.000 * *$ & $0.000 \star \star$ & $0.000 * \star$ & & -0.064 \\
\hline Plant & $0.000 * \star$ & $0.000 * \star$ & $0.000 * \star$ & $0.000 * *$ & 0.220 & $0.000 * \star$ & $0.002^{*}$ & \\
\hline $\begin{array}{l}* P<0.05 \\
* * P<0.001\end{array}$ & & & & & & & & \\
\hline
\end{tabular}

\section{Discussion}

\section{Medical Students as Team Workers}

This research shows that team worker is the most frequently preferred team role among medical students, regardless of study year, gender or specialty. This finding is somewhat surprising given that most studies define medical students and practicing medical doctors as independent decision-makers or solo performers (Gabbard 1985; Leipzig et al. 2002; Reuben et al. 2004; Horsburgh et al. 2006; Whitehead 2007; Aase et al. 2014). Therefore, we expected that medical students would score higher on action-oriented or thinking-oriented roles, than on the team worker role. For example, Walkiewicz et al. (2018) found that medical students scored significantly higher for action-oriented and thinking-oriented roles than for the team Worker role, while using the same instrument (i.e. BTRSPI) (Walkiewicz et al. 2018).

The discrepancy between our findings and those of Walkiewicz et al. (2018) is possibly due to their significantly smaller sample size (140 medical students) compared to 2293 medical students in our study. Other factors, such as geographical region (i.e. Poland versus Belgium), differences in medical curriculum (e.g. distinct approaches to stimulate teamwork skills), targeted grade (i.e. first and fifth grade versus fourth grade/first master; both in a 6-year bachelor-master curriculum) and study design (i.e. cross-sectional versus repeated cross-sectional) may have also contributed to the differences in results.

Further, our study examined the self-perception of team behaviour, while other studies focused on attitudes towards teamwork (Leipzig et al. 2002), ideas on interprofessional collaborations (Aase et al. 2014) or views on interdisciplinary team trainings (Reuben et al. 2004). These studies therefore addressed other dimensions of teamwork, which is a multifaceted mechanism that relies on a variety of factors (Salas et al. 2008). Consequently, our findings may complement 
rather than contradict former research. Medical students can prefer the team worker role, while at the same time being less inclined to interprofessional collaboration and perceiving themselves as independent decision-makers.

Another distinction is that our research took place relatively early in the careers of medical doctors (i.e. first year master students), as opposed to other studies that examined medical residents (Leipzig et al. 2002) or practicing medical doctors (Gabbard 1985; Reuben et al. 2004). This could mean that many medical students start their education as team workers, although medical education does not nurture and stimulate these qualities sufficiently. Despite the fact that our data are insufficient to corroborate this hypothesis and, hence, longitudinal studies are needed, Coulehan and Williams (2001) provide some preliminary evidence. They found that parts of medical education lead to increased detachment and selfinterest, even among students who started with qualities such as altruism and compassion (Coulehan and Williams 2001). Other studies add that first year bachelor medical students score higher on empathy compared to their third and fourth year counterparts, implying a potential reduction in empathy throughout medical education (Chen et al. 2007; Newton et al. 2008; Hojat et al. 2009; Lim et al. 2013).

Whitehead (2007) found that there still exist multiple barriers to stimulating teamwork in medical education, both in the explicit (i.e. overtly introducing certain values in courses) and the implicit (i.e. hidden or informal culture) curriculum. For instance, when medical educators and policy makers design and implement teamwork initiatives, they should also address hierarchical relations and medical doctors' expert status and decision-making responsibilities. It is crucial to explore how effective teamwork can occur within these hierarchical settings, as well as how medical students can be trained to accept and share responsibilities. In addition, teamwork values trained in the explicit curriculum should be reflected in the clinical setting (implicit curriculum), because a divergence between training and clinical setting is expected to discourage teamwork (Whitehead 2007).

\section{Team roles and Gender}

Our finding that female students score higher on the Team Worker role confirms existing literature on this topic (Anderson and Sleap 2004; Wilhelmsson et al. 2011; Kuhn and Villeval 2015). Anderson and Sleap (2004), who used the same instrument (i.e. BTRSPI), found that the Team Worker role was preferred by twice as many women as men (Anderson and Sleap 2004). Similarly, Wilhelmsson et al. (2011) found that female medical students displayed more positive beliefs toward teamwork than their male counterparts (Wilhelmsson et al. 2011). According to Kuhn and Villeval (2015) a possible explanation is that women are more attracted to teamwork, have more trust in their colleagues' abilities and less confidence in their own competence, making teamwork more beneficial.

\section{Team roles and future specialties}

Team role preferences were not consistent across medical specialties, since the representation of Team Workers was larger in future general practitioners and lower in technique-oriented specialties, with students who chose a person-centered specialty in the middle. This gradient was expected based on former studies focusing on empathy, in which medical students choosing general practice or a person-centered specialty scored higher on empathy than people choosing technique-oriented specialties (Newton et al. 2000; Chen et al. 2007). Nevertheless, it is possible that students who are more empathic are drawn to general practice or people-oriented specialties prior to their medical education, Chen et al. (2007) argue that students' career preferences may not be definitive from the start and that fostering empathy skills during medical education may have an impact on future career choices. With fewer medical students opting for a career in general practice or person-centered specialties in certain regions, a greater emphasis on empathy may stimulate to meet certain societal needs (Chen et al. 2007; Scheffler et al. 2008).

\section{Practical Implications}

Our findings contribute to an increased scientific understanding of how medical students perceive themselves in relation to their professional team roles, and how this is related to gender and specialty. There are several potential implications for policy makers, curriculum designers and medical teachers. First, former studies have shown that perceptions may result 
from experiences in the past and that people who have positive perceptions about teamwork tend to be more committed to it (Puente-Palacios and De Souza 2018). Hence, providing positive teamwork experiences throughout the medical curriculum may not only improve perceptions about teamwork, but also raise existing levels of commitment.

Second, if the current medical curriculum does not sufficiently encourage teamwork and empathy skills (Newton et al. 2000; Coulehan and Williams 2001; Chen et al. 2007; Whitehead 2007; Hojat et al. 2009; Lim et al. 2013), the stimulation of these skills on all stages (i.e. from the admission process to curricula to residency) and all levels (i.e. explicit and implicit curricula) should be prioritized. For example, from the beginning medical students should be engaged in problem-solving exercises with students from other healthcare professions (e.g. nursing or public health) (Runge 2017). In the implicit curriculum, policy makers, curriculum designers and medical educators need to be aware of the existing hierarchical relations and develop strategies to empower medical students (Goldie 2012). Role models and mentors play an important part in this process through demonstration and how to behave effectively in health care teams (Goldie 2012). Moreover, the provision of adequate feedback is recommended, not only on clinical knowledge, but also on team work and empathy skills. In addition, medical students need to be encouraged to be self-reflective on their professional team role and discuss potential role conflicts with mentors or peers (Goldie 2012).

\section{Strengths and Limitations}

An important strength of this research includes our large sample size $(n=2293)$. We were able to collect data consistently from a large group of medical students over a five-year period, which increases the generalizability of the results.

Furthermore, our research provides valuable information on medical students' self-perceived team roles, which can be used to create new research questions or form hypotheses on cause-and-effect relationships (e.g. between medical education curricula and team work behaviour/skills). Nevertheless, we should also note several limitations of our research. First, our study had a repeated cross-sectional design, which might be prone to cohort effects. Nonetheless, our results have remained consistent over five consecutive years, indicating limited cohort bias. Second, the BTRSPI is an online questionnaire that measures students' perceptions of their own behaviour. Self-rapportage is known to be prone to social desirability bias, although Cheung and Chan (2002) state that the ipsative scoring of the BTRSPI can reduce it. Third, the BTRSPI's ipsative scoring form has the disadvantage that respondents are not familiar with this type of measurement, which can result in potential errors (Cheung and Chan 2002). Fourth, the questionnaire was presented to the participants as part of a group assignment during their medical education. However, further research is necessary whether these findings can be applied and generalized to multidisciplinary healthcare teams.

\section{Conclusions}

Our results show that team worker is the most preferred team role among medical students, regardless of study year, gender or specialty. This is encouraging due to the increased importance of multidisciplinary teams in our healthcare system. Nevertheless, medical education should continue to nurture and stimulate teamwork skills throughout the entire curriculum. A work environment that puts greater emphasis on collective performances will foster interprofessional collaborations, reduce medical errors and ultimately improve our healthcare system.

\section{Abbreviations}

BTRSPI: Belbin Team Role Self Perception Inventory

CanMEDS: Canadian Medical Educational Directives for Specialists

KU Leuven: University of Leuven

GP: General Practitioners

Page $11 / 15$ 
PS: Person-oriented Specialties

TS: Technique-oriented Specialties

\section{Declarations}

Ethics approval and consent to participate

The submission of the questionnaire was part of a curriculum activity that did not require approval from the Ethics Committee. For the analysis of associations of team roles with gender and specialty, ethical approval was obtained from the Social and Societal Ethics Committee of the KU Leuven (G-2020-1632).

Consent for publication

Not applicable.

Availability of data and materials

The datasets used and/or analysed during the current study are available from the corresponding author on reasonable request.

\section{Competing interests}

The authors declare that they have no competing interests

Funding

No funding was provided to conduct this study.

\section{Authors' contributions}

All authors meet the ICMJE criteria. AB gave substantial contributions to the design of the work, and to the analysis and interpretation of the data for the work. She drafted the work and made the first data interpretation together with MR. LG gave substantial contributions to the design and fundamental ideas of the work, and the interpretation of the results. He critically revised the work and provided important insights. In addition, MR, KH, CM and MD made substantial contributions to the conception, acquisition, analysis and interpretation of the data for the work; they critically revised the work for important intellectual content. All authors read and approved the final manuscript; and agreed to be accountable for all aspects of the work in ensuring that questions related to the accuracy or integrity of any part of the work were appropriately investigated.

\section{Acknowledgements}

The authors acknowledge the practical support of the 'Educational support office of the Faculty of Medicine' of the Catholic University of Leuven with regard to data collection (first master students) and the provision of additional data (specialism choice).

\section{References}

1. Aase I, Hansen BS, Aase K. 2014. Norwegian nursing and medical students' perception of interprofessional teamwork: A qualitative study. BMC Med Educ. 14(1). doi:10.1186/1472-6920-14-170.

2. Akoglu H. 2018. User's guide to correlation coefficients. Turkish J Emerg Med. 18(3):91-93.

doi:10.1016/j.tjem.2018.08.001.

Page $12 / 15$ 
3. Anderson N, Sleap S. 2004. An evaluation of gender differences on the Belbin team role self-perception inventory. J Occup Organ Psychol. 77(3):429-437. doi:10.1348/0963179041752637.

4. Aritzeta A, Swailes S, Senior B. 2007. Belbin's team role model: Development, validity and applications for team building. J Manag Stud. 44(1):96-118. doi:10.1111/j.1467-6486.2007.00666.x.

5. Belbin M. 2012. Team roles at work.

6. Borges NJ, Richard G V. 2018. Using the Delphi Method to Classify Medical Specialties. Career Dev Q. 66(1):85-90. doi:10.1002/cdq.12124.

7. Chakraborti C, Boonyasai RT, Wright SM, Kern DE. 2008. A systematic review of teamwork training interventions in medical student and resident education. J Gen Intern Med. 23(6):846-853. doi:10.1007/s11606-008-0600-6.

8. Chandrashekar A, Mohan J. 2019. Preparing for the National Health Service: the importance of teamwork training in the United Kingdom medical school curriculum. Adv Med Educ Pract. 10:679-688.

9. Chen D, Lew R, Hershman W, Orlander J. 2007. A cross-sectional measurement of medical student empathy. J Gen Intern Med. 22(10):1434-1438. doi:10.1007/s11606-007-0298-x.

10. Cheung MWL, Chan W. 2002. Reducing uniform response bias with ipsative measurement in multiple-group confirmatory factor analysis. Struct Equ Model. 9(1):55-77. doi:10.1207/S15328007SEM0901_4.

11. Colebatch R, Zeina M, Jones AE. 2019. Shifting the focus from academic achievement. Clin Teach. 16(1):83. doi:10.1111/tct.12956.

12. Coulehan J, Williams PC. 2001. Vanquishing virtue: The impact of medical education. Acad Med. 76(6):598-605. doi:10.1097/00001888-200106000-00008.

13. Frank JR, Danoff D. 2007. The CanMEDS initiative: Implementing an outcomes-based framework of physician competencies. Med Teach. 29(7):642-647. doi:10.1080/01421590701746983.

14. Frank JR, Snell L, Sherbino J. 2015. CanMEDS 2015: Physician Competency Framework. Ottawa. http://www.royalcollege.ca/portal/page/portal/rc/canmeds/resources/publications.

15. Gabbard GO. 1985. The Role of Compulsiveness in the Normal Physician. JAMA J Am Med Assoc. 254(20):29262929. doi:10.1001/jama.1985.03360200078031.

16. Goldie J. 2012. The formation of professional identity in medical students: Considerations for educators. Med Teach. 34(9). doi:10.3109/0142159X.2012.687476.

17. Hall P. 2005. Interprofessional teamwork: Professional cultures as barriers. J Interprof Care. 19(SUPPL. 1):188-196. doi:10.1080/13561820500081745.

18. Hall P, Weaver L. 2001. Interdisciplinary education and teamwork: A long and winding road. Med Educ. 35(9):867-875. doi:10.1046/j.1365-2923.2001.00919.x.

19. Hojat M, Bianco JA, Mann D, Massello D, Calabrese LH. 2015. Overlap between empathy, teamwork and integrative approach to patient care. Med Teach. 37(8):755-758. doi:10.3109/0142159X.2014.971722.

20. Hojat M, Vergare MJ, Maxwell K, Brainard G, Herrine SK, Isenberg GA, Veloski J, Gonnella JS. 2009. The devil is in the third year: A longitudinal study of erosion of empathy in medical school. Acad Med. 84(9):1182-1191. doi:10.1097/ACM.0b013e3181b17e55.

21. Horsburgh M, Perkins R, Coyle B, Degeling P. 2006. The professional subcultures of students entering medicine, nursing and pharmacy programmes. J Interprof Care. 20(4):425-431. doi:10.1080/13561820600805233.

22. KU Leuven. 2021. Medical Education in Belgium: structure and vision. [accessed 2021 Mar 30]. https://med.kuleuven.be/en/study/incomingstudents/medical-education-in-belgium.

23. Kuhn P, Villeval MC. 2015. Are women more attracted to co-operation than men? Econ J. 125(582):115-140. doi:10.1111/ecoj.12122. 
24. Leipzig RM, Hyer K, Ek K, Wallenstein S, Vezina ML, Fairchild S, Cassel CK, Howe JL. 2002. Attitudes toward working on interdisciplinary healthcare teams: A comparison by discipline. J Am Geriatr Soc. 50(6):1141-1148. doi:10.1046/j.1532-5415.2002.50274.x.

25. Lim BT, Moriarty H, Huthwaite M, Gray L, Pullon S, Gallagher P. 2013. How well do medical students rate and communicate clinical empathy? Med Teach. 35(2). doi:10.3109/0142159X.2012.715783.

26. Mendo-Lázaro S, Polo-del-Río MI, Iglesias-Gallego D, Felipe-Castaño E, León-del-Barco B. 2017. Construction and validation of a measurement instrument for attitudes towards teamwork. Front Psychol. 8(JUN):1-10. doi:10.3389/fpsyg.2017.01009.

27. Montgomery A, Spânu F, Bəban A, Panagopoulou E. 2015. Job demands, burnout, and engagement among nurses: A multi-level analysis of ORCAB data investigating the moderating effect of teamwork. Burn Res. 2(2-3):71-79. doi:10.1016/j.burn.2015.06.001.

28. Newton BW, Barber L, Clardy J, Cleveland E, O'Sullivan P. 2008. Is there hardening of the heart during medical school? Acad Med. 83(3):244-249. doi:10.1097/ACM.0b013e3181637837.

29. Newton BW, Savidge MA, Barber L, Cleveland E, Clardy J, Beeman G, Hart T. 2000. Differences in medical students' empathy. Acad Med. 75(12):1215. doi:10.1097/00001888-200012000-00020.

30. Puente-Palacios K, De Souza MGS. 2018. Professional self-concept: Prediction of teamwork commitment. Rev Psicol. 36(2):465-490. doi:10.18800/psico.201802.003.

31. R Core Team. 2020. R: A language and environment for statistical computing. R Foundation for Statistical Computing. https://www.r-project.org/.

32. Reuben DB, Levy-Storms L, Yee MN, Lee M, Cole K, Waite M, Nichols L, Frank JC. 2004. Disciplinary split: A threat to geriatrics interdisciplinary team training. J Am Geriatr Soc. 52(6):1000-1006. doi:10.1111/j.1532-5415.2004.52272.x.

33. Ringsted C, Hansen TL, Davis D, Scherpbier A. 2006. Are some of the challenging aspects of the CanMEDS roles valid outside Canada? Med Educ. 40(8):807-815. doi:10.1111/j.1365-2929.2006.02525.x.

34. Rosen MA, DiazGranados D, Dietz AS, Benishek LE, Thompson D, Pronovost PJ, Weaver SJ. 2018. Teamwork in Healthcare: Key Discoveries Enabling Safer, High- Quality Care. Am Psychol. 73(4):433-450. doi:10.1016/j.physbeh.2017.03.040.

35. Runge MS. 2017. Opinion: Modern Medicine Is a Team Sport. How Students - and Schools - Should Adapt. Michigan Med Heal Lab. [accessed 2021 Aug 23]. https://labblog.uofmhealth.org/med-u/opinion-modern-medicine-a-team-sporthow-students-and-schools-should-adapt.

36. Saba GW, Villela TJ, Chen E, Hammer H, Bodenheimer T. 2012. The myth of the lone physician: Toward a collaborative alternative. Ann Fam Med. 10(2):169-173. doi:10.1370/afm.1353.

37. Salas E, DiazGranados D, Weaver SJ, King H. 2008. Does team training work? Principles for health care. Acad Emerg Med. 15(11):1002-1009. doi:10.1111/j.1553-2712.2008.00254.x.

38. Scheffler RM, Liu JX, Kinfu Y, Dal Poz MR. 2008. Forecasting the global shortage of physicians: An economic- and needs-based approach. Bull World Health Organ. 86(7):516-523. doi:10.2471/BLT.07.046474.

39. Walkiewicz M, Sowińska K, Tartas M. 2018. Medical studies, team roles and emotional intelligence. Fam Med Prim Care Rev. 20(1):71-77. doi:10.5114/fmpcr.2018.73708.

40. Whitehead C. 2007. The doctor dilemma in interprofessional education and care: How and why will physicians collaborate? Med Educ. 41(10):1010-1016. doi:10.1111/j.1365-2923.2007.02893.x.

41. Wilhelmsson M, Ponzer S, Dahlgren LO, Timpka T, Faresjö T. 2011. Are female students in general and nursing students more ready for teamwork and interprofessional collaboration in healthcare? BMC Med Educ. 11(1). doi:10.1186/14726920-11-15.

42. Yates J. 2012. When did they leave, and why? A retrospective case study of attrition on the Nottingham undergraduate medical course. BMC Med Educ. 12(1). doi:10.1186/1472-6920-12-43. 
Figures

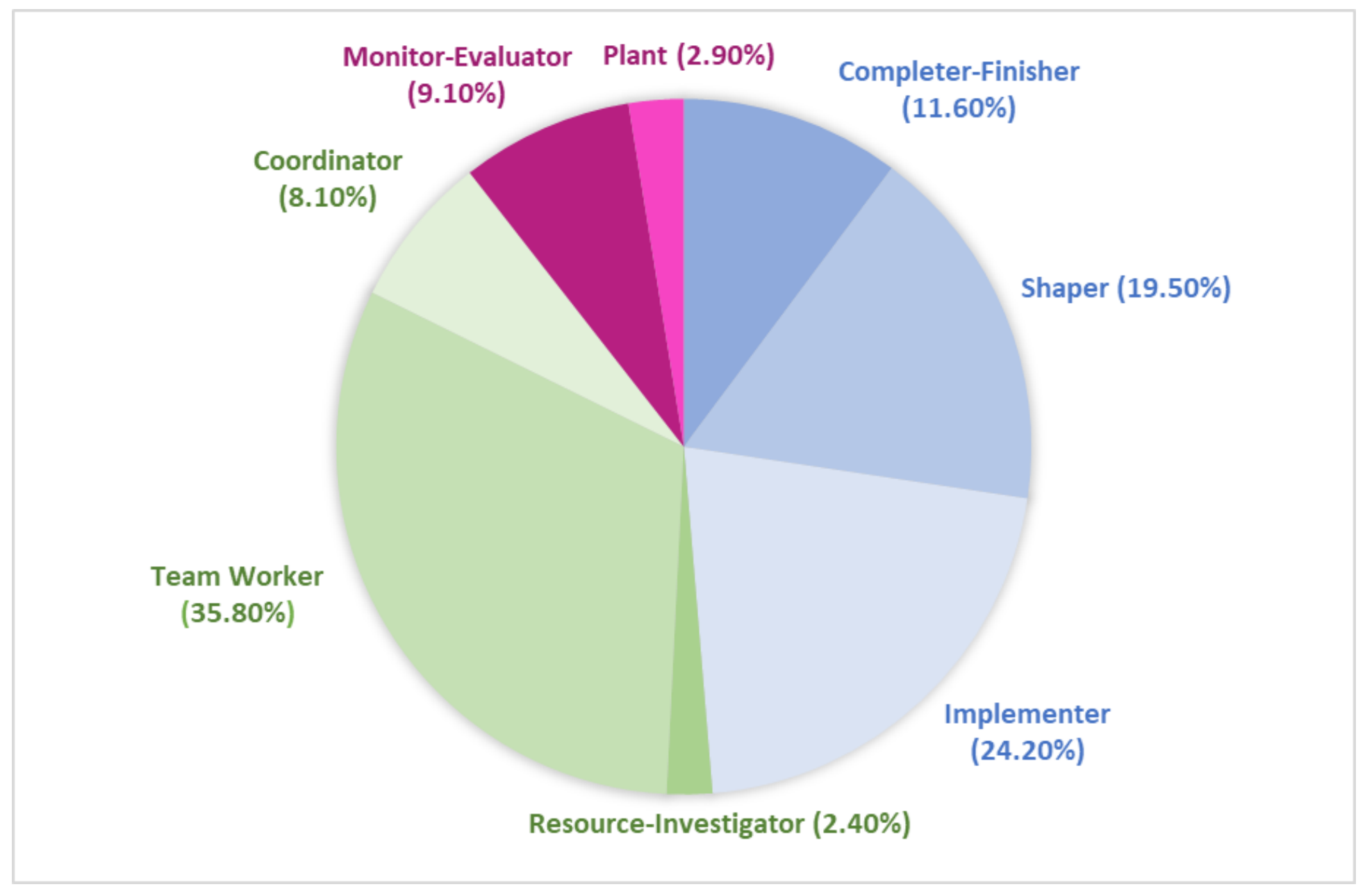

Figure 1

Team Roles 